\title{
Spatially Refined Aerosol Direct Radiative Forcing Efficiencies
}

\author{
Daven K. Henze, ${ }^{\dagger} *$ Drew T. Shindell, ${ }^{\ddagger}$ Farhan Akhtar, ${ }^{\S}$ Robert J. D. Spurr, ${ }^{\|}$Robert W. Pinder, ${ }^{\S}$ \\ Dan Loughlin, ${ }^{\S}$ Monika Kopacz, ${ }^{\perp}$ Kumaresh Singh, ${ }^{\#}$ and Changsub Shim
}

\author{
${ }^{\dagger}$ Department of Mechanical Engineering, University of Colorado, Boulder, Colorado 80309, United States \\ ${ }^{\ddagger}$ NASA Goddard Institute for Space Studies (GISS) and Columbia University, New York, New York 10025, United States \\ ${ }^{\S}$ U.S. EPA Office of Research and Development, Research Triangle Park, North Carolina, United States \\ "RT Solutions Inc., 9 Channing Street, Cambridge, Massachusetts 02138, United States \\ ${ }^{\perp}$ NOAA Climate Program Office, Silver Spring, Maryland, United States \\ \# Department of Computer Science, Virginia Polytechnic Institute and State University, Blacksburg, Virginia, United States

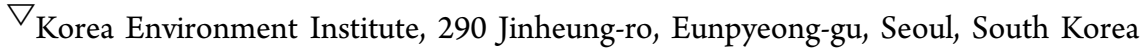

\section{Supporting Information}

\begin{abstract}
Global aerosol direct radiative forcing (DRF) is Largest BC emissions changes an important metric for assessing potential climate impacts of future emissions changes. However, the radiative consequences of emissions perturbations are not readily quantified nor well understood at the level of detail necessary to assess realistic policy options. To address this challenge, here we show how adjoint model sensitivities can be used to provide highly spatially resolved estimates of the DRF from emissions of black carbon (BC), primary organic carbon (OC), sulfur dioxide $\left(\mathrm{SO}_{2}\right)$, and ammonia $\left(\mathrm{NH}_{3}\right)$, using the example of emissions

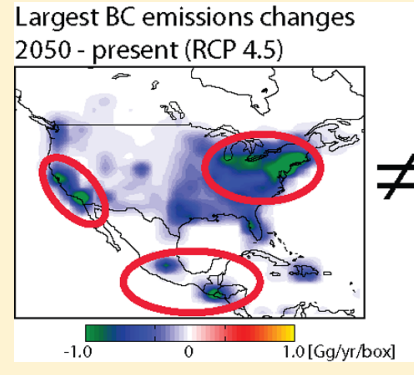
Largest contributions to aerosol radiative forcing from each sector and country following multiple Representative Concentration Pathway (RCPs). The radiative forcing efficiencies of many individual emissions are found to differ considerably from regional or sectoral averages for $\mathrm{NH}_{3}, \mathrm{SO}_{2}$ from the power sector, and $\mathrm{BC}$ from domestic, industrial, transportation and biomass burning sources. Consequently, the amount of emissions controls required to attain a specific DRF varies at intracontinental scales by up to a factor of 4 . These results thus demonstrate both a need and means for incorporating spatially refined aerosol DRF into analysis of future emissions scenario and design of air quality and climate change mitigation policies.
\end{abstract}

\section{INTRODUCTION}

Anthropogenic enhancements to aerosol abundances have significantly influenced climate since preindustrial times through their combined direct radiative forcing (DRF) of $-0.5 \pm-0.4 \mathrm{~W} \mathrm{~m}^{-2}{ }^{1}$. Changes to aerosol and aerosol precursor emissions are expected, either intentionally or inadvertently, to exert further influence on climate in coming decades. ${ }^{2-4}$ Such emissions changes may encompass a range of impacts to multiple source sectors, in multiple regions, altering the abundances of different types of aerosols and greenhouse gases with several competing consequences. Policy makers are thus concerned with refining our understanding of the link between emissions changes and radiative forcing.

However, estimating the radiative forcing of numerous, detailed future emissions scenarios is challenging for several reasons. First, radiative effects of aerosols and other short-lived climate forcers (SLCFs) are spatially variable, so unlike emissions of long-lived greenhouse gases, the location of their sources modulates their impact. Hence, recent studies have moved from abundance-based metrics of radiative forcing to quantifying the forcing of emissions from specific regions and sectors. ${ }^{5-14}$ Second, accounting for the full range of aerosol interactions and feedbacks, from the aerosol indirect ${ }^{15,16}$ and semidirect ${ }^{17,18}$ effects to aerosol-gas interactions, ${ }^{19,20}$ requires lengthy model calculations. Lastly, emissions projections for future scenarios themselves are inherently uncertain. To address all of these issues, ensembles of detailed climate model calculations could be performed across a wide spectrum of regional, sector and species specific emissions scenarios. However, using standard approaches, it is too computationally expensive to separate impacts at a source-specific level across numerous scenarios in detailed models.

Here we present, validate and apply an entirely new approach to quantifying the radiative forcing impacts of emissions scenarios at a resolution several orders of magnitude finer than previously considered. Presently we focus exclusively on aerosol direct radiative forcing as a necessary first step toward

Received: May 17, 2012

Revised: August 8, 2012

Accepted: August 10, 2012

Published: August 10, 2012 
understanding the broader impacts of aerosols. Sector and region-specific direct global aerosol radiative forcing may be more important than global indirect effects, ${ }^{14}$ hence the DRF alone is significant enough to provide valuable guidance toward more detailed assessments. Previous studies attributing radiative forcing to sources at regional scales have relied on multiple model evaluations wherein subsets of emissions are perturbed sequentially, a method that becomes prohibitively expensive as the number of emissions sets considered becomes large $(>100)$. In contrast, adjoint modeling is a means by which variations in a model response function are propagated backward in time through an auxiliary (adjoint) set of model equations, ultimately yielding the sensitivities of this function with respect to all model inputs simultaneously at a computational cost independent of the number of inputs considered. ${ }^{21,22}$ Here we introduce this approach as a means of calculating the sensitivities of direct aerosol radiative effects with respect to emissions. This provides an estimate of the instantaneous global aerosol DRF from emissions of every aerosol and aerosol precursor emission, from each source sector, in each grid cell of the model several orders of magnitude faster than conventional methods.

\section{MATERIALS AND METHODS}

In the following sections we describe how a chemical transport model and its adjoint are used to calculate DRF sensitivities.

2.1. GEOS-Chem. GEOS-Chem (http://www.geos-chem. org) is a chemical transport model driven with assimilated meteorology from the Goddard Earth Observing System (GEOS) of the NASA Global Modeling and Assimilation Office (GMAO). GEOS-5 meteorological data sets are downsampled to facilitate detailed simulation of tropospheric gasphase chemistry, ${ }^{23}$ here run at $2^{\circ} \times 2.5^{\circ}$ resolution globally using model version 8-02-01 with relevant patches and updates through v9. Aerosols in GEOS-Chem ${ }^{24,25}$ are treated as an external mixture. The size distributions are log-normal with fixed width and dry mode diameters, subject to hygroscopic growth. Bulk partitioning of secondary inorganic species is calculated with the RPMARES thermodynamic scheme. ${ }^{26}$ Aging of primary black carbon from hydrophobic to hydrophilic occurs with an $e$-folding time of 1.15 days. Aerosols are coupled with oxidant simulations through heterogeneous chemistry ${ }^{27,28}$ and aerosol effects on photolysis rates. ${ }^{29}$ Global anthropogenic emissions of $\mathrm{NO}_{x}$ and $\mathrm{SO}_{x}$ are from EDGAR ${ }^{30}$ and from Bond et al. $^{31}$ for carbonaceous aerosol, overwritten by regional inventories where available. ${ }^{32} \mathrm{NH}_{3}$ emissions are described in Park et al., ${ }^{25}$ monthly biomass burning emissions are from GFEDv2 ${ }^{33}$ and biofuel emissions from Yevich and Logan. ${ }^{34}$ Dry deposition is calculated using a resistance in series approach $^{35}$ and wet losses include in-cloud and below-cloud rainout and convective scavenging. ${ }^{27,36}$

Aerosol optical properties in GEOS-Chem ${ }^{29,37}$ follow the Global Aerosol Data Set (GADS). ${ }^{38,39}$ All aerosol species are assumed to be externally mixed, which will likely lead to underestimation of aerosol absorption. ${ }^{40}$ To compensate, we enforce a BC mass absorption of 1.5. ${ }^{41}$ Calculation of aerosol radiative forcing employs five spectral bands spanning 4400 to $32260 \mathrm{~cm}^{-1} \cdot{ }^{37}$ The LIDORT radiative transfer model ${ }^{42,43}$ is used to calculate the top of the atmosphere (TOA) radiative flux, using surface reflectances from $\mathrm{GOME}^{44}$ that span from $12987 \mathrm{~cm}^{-1}$ to $27027 \mathrm{~cm}^{-1}$ and are extrapolated to cover the shortwave spectrum considered here. Unless noted otherwise, calculations are for all-sky conditions wherein forcing is masked by the GMAO cloud fraction of each column. The resulting combined global yearly average AOD at $500 \mathrm{~nm}$ from ammonium sulfate, ammonium nitrate, $\mathrm{BC}$, and $\mathrm{OC}$ of 0.078 is consistent with previous modeling studies, ${ }^{45}$ which reported global average AOD at $550 \mathrm{~nm}$ for sulfate, BC, and primary organic matter $(=1.4 \times \mathrm{OC})$ of 0.057 and ranging by more than a factor of 2 among models with unified emissions. The preindustrial (1850) to present (2000) aerosol all-sky TOA DRF is calculated to be $-0.47 \mathrm{~W} \mathrm{~m}^{-2}$ using emissions from the Climate Model Intercomparison Program (CMIP5) ${ }^{46}$ in support of the fifth Intergovernmental Panel on Climate Change (IPCC) report. The breakdown of this forcing into contributions from specific regions and sectors is provided in Supporting Information (SI) Figure S4. Excluding biomass burning, the entire aerosol DRF due to constant 2000 emissions is only slightly (3\%) greater than the 2000 relative to $1850 \mathrm{DRF}$, so that these results also provide a useful perspective on the impacts of current emissions on future climate. These values are broadly consistent with those in the fourth IPCC report, ${ }^{1}$ considering (a) that we likely overestimate $\mathrm{NH}_{3}$ forcing (see SI Figure S3) and (b) that the IPCC reports abundance-based forcings, whereas here we consider emissions based forcings, which, for example, are lower for $\mathrm{SO}_{2}$ than for aerosol sulfate. ${ }^{20}$

2.2. GEOS-Chem Adjoint Sensitivities of Radiative Forcing. An adjoint model is a set of equations auxiliary to a forward model that are used to efficiently calculate sensitivities of a scalar model response function with respect to numerous model inputs. ${ }^{21}$ The adjoint of GEOS-Chem is presently the only such model to include gas-phase chemistry, heterogeneous chemistry, black and organic primary aerosol, and sulfateammonium-nitrate formation chemistry and thermodynamics, ${ }^{47}$ with code updates following the relevant parts of the GEOSChem forward model up through version v9. In this work we extend the GEOS-Chem adjoint to include calculation of sensitivities of a model response, $\mathcal{J}(\boldsymbol{\sigma})$, defined to be the direct radiative forcing of aerosols from present-day anthropogenic emissions, $\boldsymbol{\sigma}$,

$$
\mathcal{J}(\boldsymbol{\sigma})=\uparrow F\left(\boldsymbol{\sigma}^{0}\right)-\uparrow F\left(\boldsymbol{\sigma}^{0}+\boldsymbol{\sigma}\right)
$$

where $\uparrow F$ is the global upward radiative flux at the top of the atmosphere and $\sigma^{0}$ is the vector of preindustrial emissions. Calculation of adjoint sensitivities $\left(\lambda_{\sigma}\right)$ is initiated with expansion of the derivative of the forcing with respect to aerosol concentrations at each time step using the chain-rule,

$$
\left(\frac{\partial \mathcal{J}}{\partial \mathbf{c}^{n}}\right)^{T}=\left(\mathbf{M}_{\mathrm{a}}^{n}\right)^{T}\left(\mathbf{M}_{\mathrm{opt}}^{n}\right)^{T}\left(\mathbf{M}_{\mathrm{rtm}}^{n}\right)^{T} \mathbf{m}_{\mathrm{w}} \frac{\partial \mathcal{J}(\boldsymbol{\sigma})}{\partial \uparrow F\left(\boldsymbol{\sigma}^{0}+\boldsymbol{\sigma}\right)}
$$

Evaluating this equation from right to left, the $(\partial \mathcal{J}(\boldsymbol{\sigma})) /\left(\partial \uparrow F\left(\boldsymbol{\sigma}^{0}+\boldsymbol{\sigma}\right)\right)$ term is $-1 . \mathbf{m}_{\mathrm{w}}$ is a weighting vector that accounts for the contribution of the radiative flux in a particular column at a single time step to the global yearly average flux, including the column cloud fraction for all-sky calculations. $\mathbf{M}_{\mathrm{rtm}}$ is the Jacobian of the instantaneous TOA upward radiative flux in a single column with respect to the aerosol optical thickness, scattering albedo and phase function in each vertical level of that column, calculated analytically by LIDORT. ${ }^{42,43} \mathbf{M}_{\text {opt }}$ is the Jacobian of these optical properties with respect to the aerosol wet diameter for each species in each cell. $\mathbf{M}_{\mathrm{a}}$ is the Jacobian of the aerosol wet diameter with respect to the aerosol mass concentrations, $\mathbf{c}^{n}$, where $\mathbf{c}^{n}$ is the vector of all $K$ tracer concentrations, $\mathbf{c}^{n}=\left[c_{1}^{n}, \ldots, c_{K}^{n}\right]^{T}$ at time step 
(a) $\mathrm{BC}$

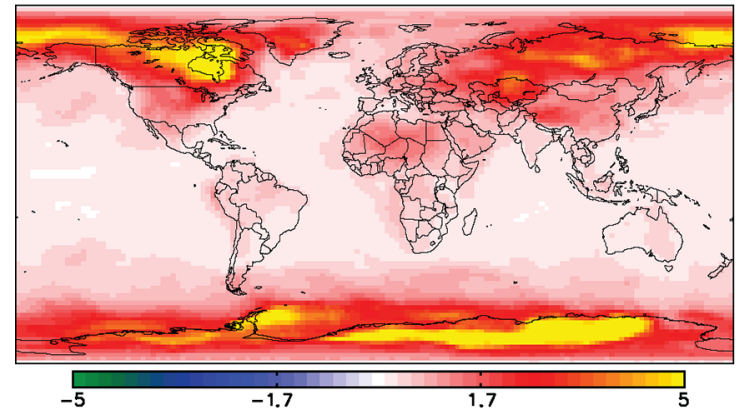

(c) $\mathrm{OC}$

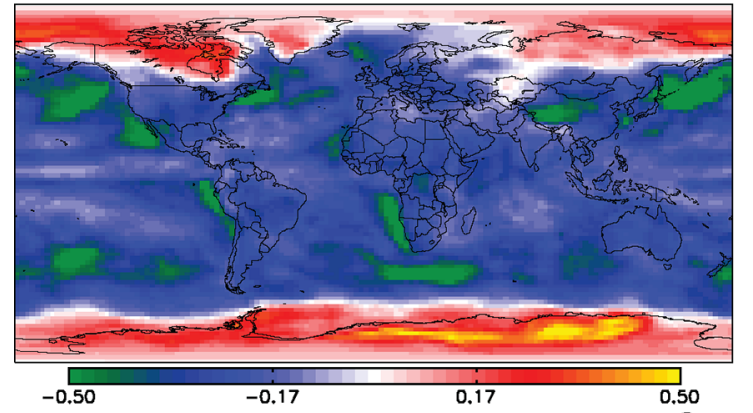

(b) $\mathrm{SO}_{2}$

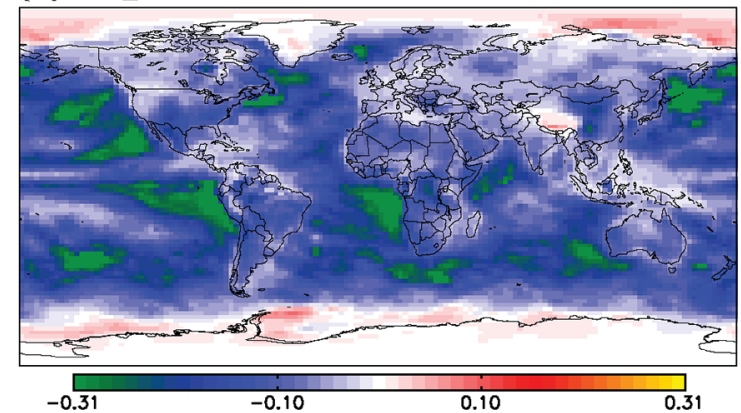

(d) $\mathrm{NH}_{3}$

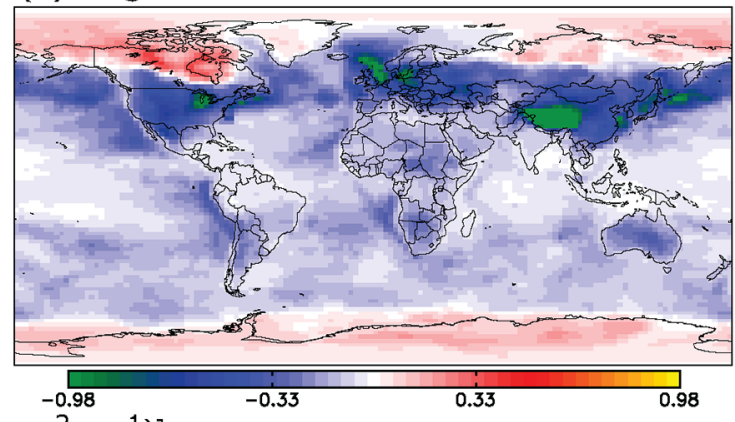

Figure 1. Yearly average radiative forcing efficiencies for (a) BC, (b) $\mathrm{SO}_{2},(\mathrm{c}) \mathrm{OC}$, and (d) $\mathrm{NH}_{3}$. Values in a particular grid cell show the response of global aerosol DRF to perturbations of emissions in that grid cell.

$n=0, \ldots, N . \mathbf{M}_{\text {opt }}$ is calculated using analytic derivatives from a linearized Mie scattering calculation. The product of $\left(\mathbf{M}_{\mathrm{a}}^{n}\right)^{T}$ with the vector $\left(\mathbf{M}_{\mathrm{opt}}^{n}\right)^{T}\left(\mathbf{M}_{\mathrm{rtm}}^{n}\right)^{T} \mathbf{m}_{\mathrm{w}}(\partial J(\boldsymbol{\sigma})) /\left(\partial \uparrow F\left(\boldsymbol{\sigma}^{0}+\boldsymbol{\sigma}\right)\right)$ is calculated using adjoints. The adjoint model then takes as input $\left((\partial \mathcal{J}) /\left(\partial \mathrm{c}^{n}\right)\right)^{T}$; after integrating backward in time the solution of the adjoint model is the vector of sensitivities with respect to emissions $\lambda_{\sigma}=\nabla_{\sigma} \mathcal{J}$.

To consider how radiative forcing will change owing to the difference between anthropogenic emissions in the future, $\boldsymbol{\sigma}$, and the present, $\boldsymbol{\sigma}$, the change in forcing, $\Delta \mathcal{J}=\mathcal{J}\left(\boldsymbol{\sigma}^{f}\right)-\mathcal{J}(\boldsymbol{\sigma})$, can be approximated as

$$
\Delta \mathcal{J} \approx \lambda_{\sigma}^{T} \Delta \sigma
$$

where $\Delta \sigma=\sigma^{f}-\sigma, \Delta \mathcal{J}$ is the corresponding DRF, and $\lambda_{\sigma}$ is the vector of sensitivities of $\mathcal{J}$ to these emissions from the solution of the adjoint model. Thus, $\lambda_{\sigma}$ represents a fundamental radiative forcing efficiency ( $\mathrm{W} \mathrm{m}^{-2} /$ emission) that is used to linearly estimate DRF responses for any arbitrary set of emissions perturbations. The accuracy of the adjointbased estimates is extensively validated (see SI and Figures S1 and S2); grid-level radiative forcing estimated from the adjoint sensitivities correspond well $\left(r^{2}>0.97\right)$ with changes in radiative forcing calculated explicitly using the full forward model. We also consider the extent to which linear extrapolations of adjoint sensitivities to estimate DRF are valid over a range of spatially aggregated perturbations to emissions. While nonlinearities triggered by perturbing global emissions of $\mathrm{NO}_{x}$ diminish the relationship between globally aggregated forward and adjoint sensitivities, similar tests for $\mathrm{SO}_{2}, \mathrm{BC}, \mathrm{OC}$, and $\mathrm{NH}_{3}$ are well correlated $\left(r^{2}=0.98\right)$ and have low bias, hence we restrict our assessment to these species.

\section{RADIATIVE FORCING EFFICIENCIES}

Application of the adjoint model yields radiative forcing efficiencies for each aerosol precursor emission in each grid cell, which indicate how arbitrary changes to emissions can have location-dependent impacts. Yearly average efficiencies, in (W $\left.\mathrm{m}^{-2}\right) /\left(\mathrm{kg} \mathrm{m}^{-2} \mathrm{yr}^{-1}\right)$, are constructed from 12 separate weeklong adjoint model calculations, one per month, for which the response function (eq 1 ) is the average DRF over a $24 \mathrm{~h}$ period and sensitivities are integrated backward in time for a week prior to this period. The resulting efficiencies (Figure 1) show the change in global DRF with respect to emissions perturbations in each location. The variability in the efficiencies is driven by several factors, the largest being the degree to which emissions from a particular grid cell contribute to aerosol concentrations over surfaces of low or high albedo. Variability in loss rates also plays a role; these two factors entirely govern the efficiency distribution of $\mathrm{BC}$ and OC. For $\mathrm{NH}_{3}$, the efficiency is further regulated by the degree of neutralization of the aerosols. ${ }^{48}$ For $\mathrm{SO}_{2}$, emissions that form sulfate aerosol in dry, oxidative conditions have a higher radiative forcing efficiency than emissions leading to formation of sulfate in clouds, where sulfate is more readily scavenged. Over snow, even reflective aerosols can have a positive forcing through effective enhancement of the radiative path length. Overall, the heterogeneity of the DRF efficiencies underscores the importance of spatially refined treatment of aerosol DRF.

\section{RADIATIVE FORCING OF FUTURE EMISSIONS SCENARIOS}

The spatial variability in the radiative forcing efficiencies shown in Figure 1 indicates that regionally or sectorally aggregated radiative forcing estimates could misrepresent the impacts of finer scale trends in emissions. To investigate the radiative effects of such trends, we multiply these radiative forcing 


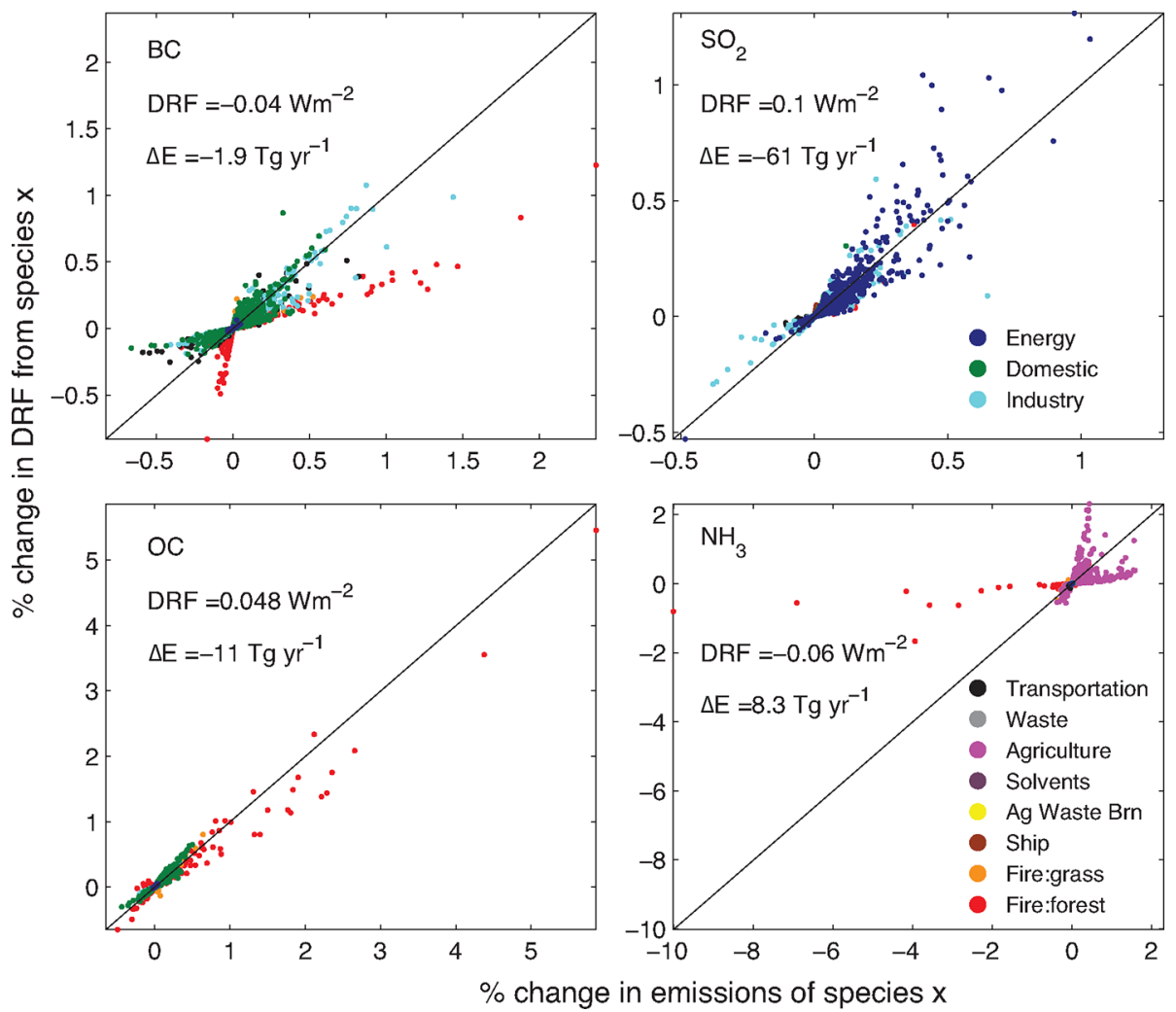

Figure 2. For RCP 4.5 in 2050 relative to 2000: percent change in emissions for a specific species in each grid cell ( $x$-axis) vs the corresponding percent change in the aerosol DRF for that specific species alone ( $y$-axis). Each panel also shows the DRF and change in emissions $(\Delta E)$ on which these percentages are based. Note that positive percentages indicate enhancements to the absolute magnitude of net DRF or $\Delta E$, while negative percentages indicate changes in the direction opposite the net DRF or $\Delta E$.

efficiencies by spatially resolved estimates of emission changes from 2000 to 2050. These changes follow Representative Concentration Pathways ( $\left.\mathrm{RCPs}^{49}\right)$, a set of stabilization scenarios employing different land-use and greenhouse gas emissions projections to meet radiative forcing targets in the year 2100 that are progressively more aggressive, with RCP 8.5 leading to the highest greenhouse gas emissions, ${ }^{50}$ followed by RCP $6.0,^{51,52}$ RCP $4.5,{ }^{53-55}$ and RCP 2.6 with the largest reductions in greenhouse gases. ${ }^{56}$ However, it is important to note that the RCPs are not derived from a common framework, and the progression of the emissions of aerosols among them are only indirectly coupled to their radiative forcing targets. Thus, differences between the RCPs can not directly be interpreted as a result of specific climate policies or socioeconomic developments.

4.1. Variability in Efficiency Vs Emissions Magnitude. The extent to which variability in DRF is driven by the magnitude of emissions changes vs the efficiency of such changes is analyzed in detail for the midrange RCP 4.5 scenario in the year 2050 relative to 2000 . Figure 2 shows the percent change in emissions in each grid cell, by species and sector, vs the percent by which RCP 4.5 emissions changes contribute to the total DRF of that particular species; the total efficiency of each sector across all locations is included as SI (Figure S3). Any negative DRF from $\mathrm{BC}$ or positive DRF from $\mathrm{SO}_{2}$, OC or $\mathrm{NH}_{3}$ indicates a location where the RCP 4.5 emissions are lower in 2050 than 2000, and vice versa.

Changes to precursor emissions of secondary aerosols have widely variable radiative impacts. There are two distinct response regimes for $\mathrm{NH}_{3}$ where DRF is not commensurate with emissions changes. Figure 3 shows the actual emissions changes and the corresponding DRFs for the $\mathrm{NH}_{3}$ agricultural sector. These two regimes correspond to increases in $\mathrm{NH}_{3}$ in parts of Africa and India where aerosol formation is not $\mathrm{NH}_{3}$ limited, compared to areas in China, Europe and the U.S., where small amounts of $\mathrm{NH}_{3}$ can lead to efficient formation of ammonium nitrate. The DRF for $\mathrm{SO}_{2}$ emissions are shown in Figure 3 to be highly variable on a grid-cell by grid-cell basis; the DRF of $0.5 \%$ changes to total $\mathrm{SO}_{2}$ emissions via the power sector may vary by a factor of 4 (from $0.25 \%$ to $1 \%$ ). However, the globally aggregated DRF of each $\mathrm{SO}_{2}$ sector closely follows their emissions change (see SI Figure S3). Thus, there could be substantial error in assuming a uniform DRF across all locations for $\mathrm{NH}_{3}$ and $\mathrm{SO}_{2}$ from the agriculture and energy sectors, respectively.

For primary carbonaceous aerosol, increases to BC emissions from the industry, domestic and transportation sectors occur mostly over sub-Saharan Africa, where BC DRF efficiency is low, leading to consistently muted DRFs. For BC emissions reductions in China, India, Europe and the U.S., the efficiency is less consistent. In total, BC emissions changes of 35\%, 19\% and $2 \%$, from industry, domestic, and transportation sectors, respectively, contribute to $46 \%, 34 \%$, and $10 \%$ of the total BC DRF, a response that is a third to a factor of 5 times larger than the corresponding emissions changes. Changes to biomass burning emissions of $\mathrm{BC}$ account for $33 \%$ of total reduction to $\mathrm{BC}$, but the contribution to $\mathrm{BC}$ DRF of the biomass burning sector as a whole is nearly neutral, as small increases to $\mathrm{BC}$ emissions in Canada and Russia of $2.3 \%$ and $1.5 \%$, respectively, have a large impact ( $15 \%$ combined) on BC DRF, which leads 


\section{(a) $\mathrm{NH}_{3}$ agricultural $\Delta$ emissions}

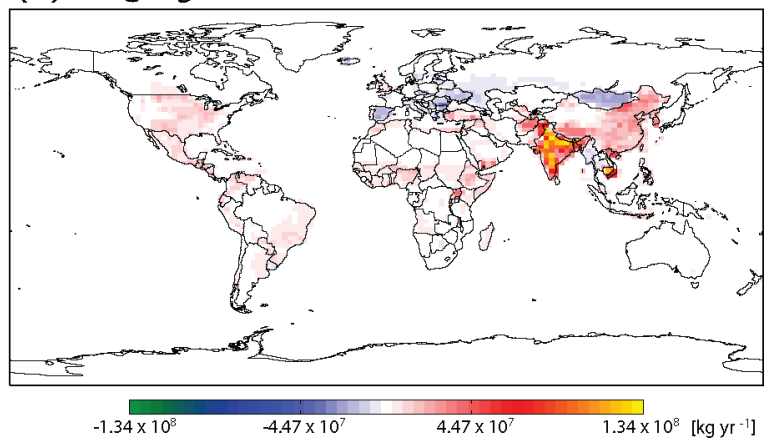

(b) DRF for $\mathrm{NH}_{3}$ agricultural emissions

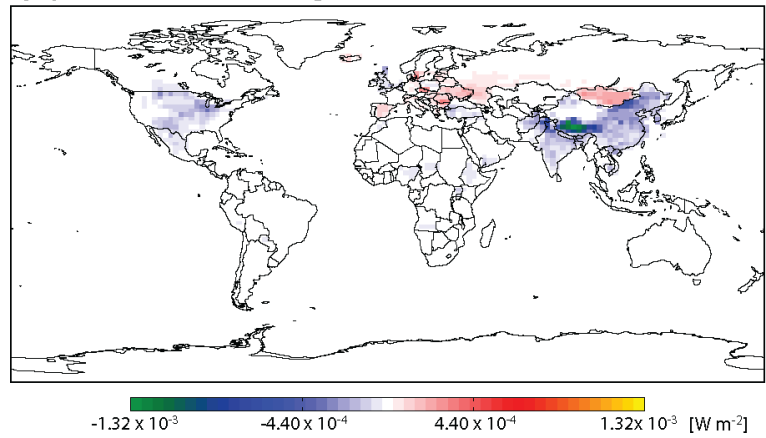

Figure 3. Top: changes to $\mathrm{NH}_{3}$ agricultural emissions for RCP 4.5 in 2050 relative to 2000 . Bottom: corresponding aerosol DRF for emissions change in each grid cell. to the steeply sloping cluster of red points in the lower left of the $\mathrm{BC}$ panel of Figure 2. The impact of OC emissions is more closely tied to emissions rates, although the total DRF efficiency of domestic and industry emissions is slightly greater than the response to biomass burning.

To further investigate both regional and sector variability, DRFs aggregated over 24 regions (http://themasites.pbl.nl/en/ themasites/image/background/regions/index.html) are shown in Figure 4. Changes to emissions from the domestic, industry, and transportation sectors have potentially large radiative forcing impacts, though the balance of effects from the absorbing vs scattering aerosols leads to net changes near zero in most regions for this scenario. Exceptions are changes to industry emissions in Southern Asia and the U.S. having a net positive DRF, and transportation having a positive DRF in China and negative DRF in Europe and the Middle East. An additional factor contributing to the total aerosol DRF is the impact of agricultural $\mathrm{NH}_{3}$ emissions in China, the U.S. and Southern Asia through promotion of secondary inorganic aerosol formation. We note this is more substantial than commonly recognized ${ }^{1}$ for a few reasons. The $\mathrm{NH}_{3}$ forcings effectively include the impacts of aerosol nitrate, as excess ammonia levels promote ammonium nitrate formation. This may be exaggerated in the GEOS-Chem adjoint, which presently does not account for formation of sodium nitrate or uptake of nitric acid by dust. Second, as discussed earlier, $\mathrm{NH}_{3}$ DRFs based on sensitivities calculated around present-day conditions do not account for any reductions in availability of
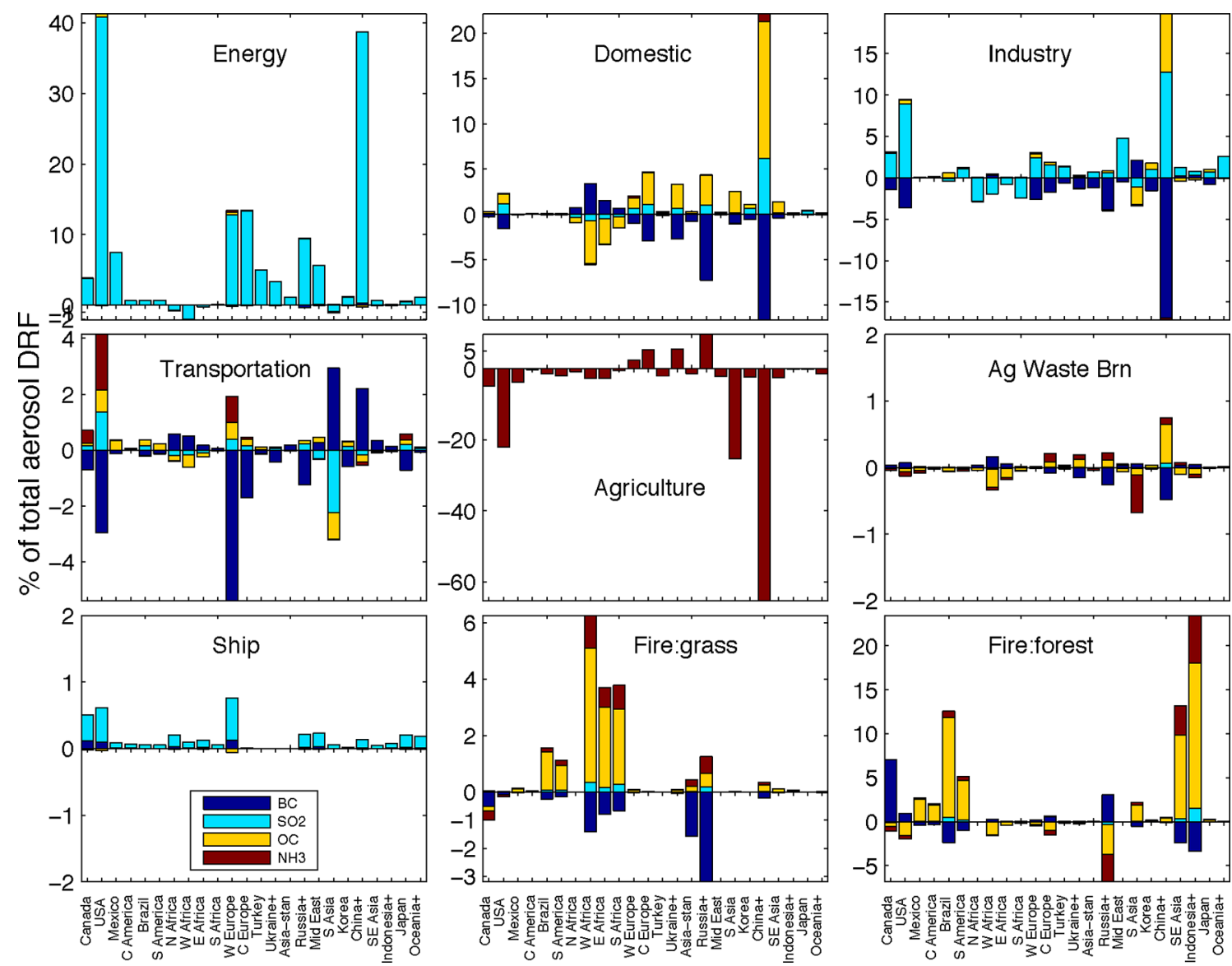

Figure 4. Aerosol DRF of RCP 4.5 in 2050 relative to 2000, for each emission sector and species, lumped by region. Percentages show the contribution of changes to emissions in each region to the total DRF of $0.05 \mathrm{~W} \mathrm{~m}^{-2}$. 

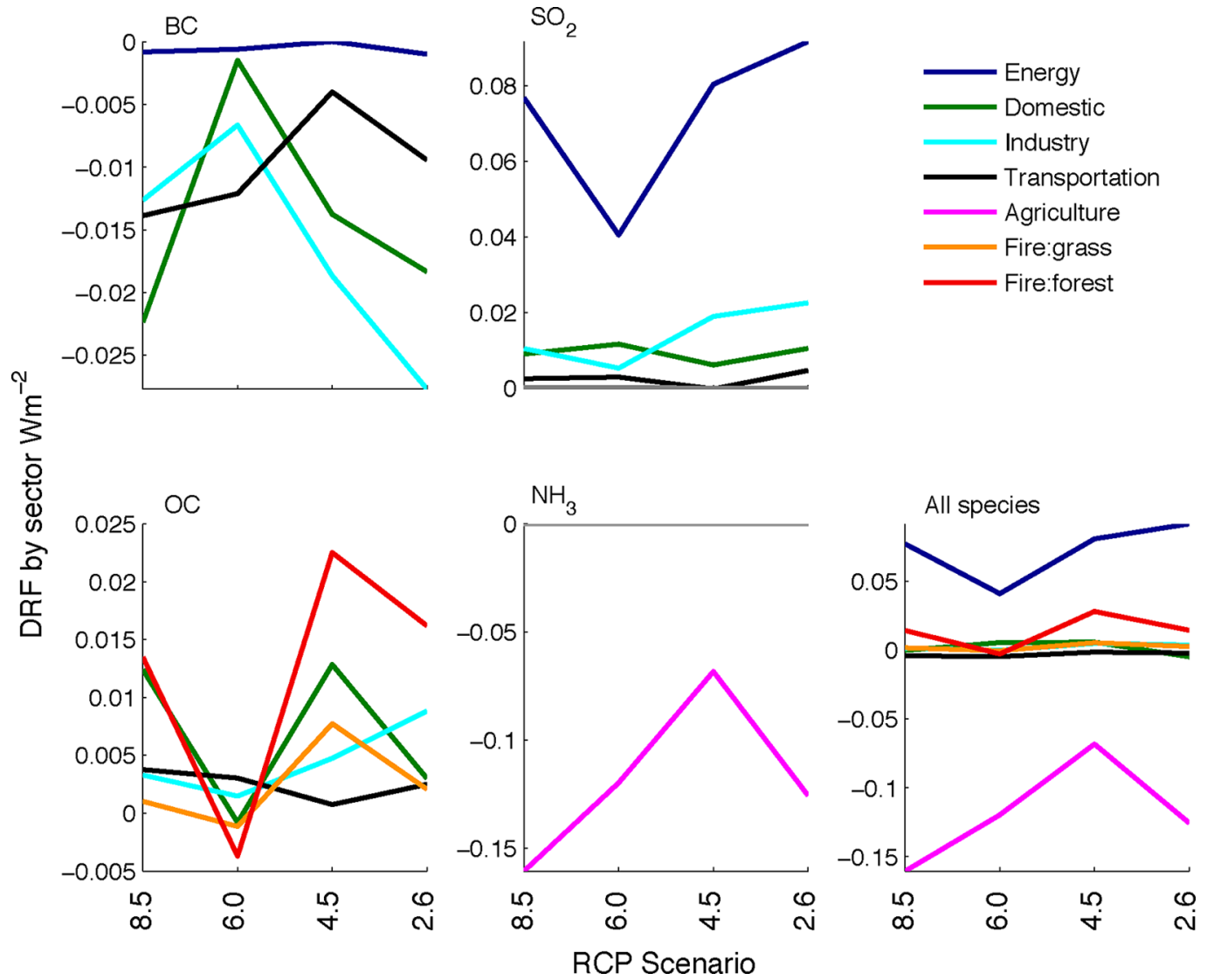

Figure 5. DRF from each sector plotted by species for RCP 8.5 through RCP 2.6, separated by species, and the total of all species.

sulfate and nitrate with which to form aerosol, and as such are likely upper estimates in many regions.

4.2. Comparison Across Scenarios. We next consider how influences from individual regions, sectors and species govern the aerosol DRFs across RCP 8.5, 6.0, 4.5, and 2.6, estimated here to have global DRFs of $-0.07,-0.08,0.05$, and $-0.02 \mathrm{~W} \mathrm{~m}^{-2}$, respectively. This multiscenario analysis is afforded through repeated application of the high-resolution DRF efficiencies without the need for numerous additional forward model calculations. The variability in the DRFs across each RCP within individual regions is provided in SI Figure S5. Previous works have noted the potential benefit of reducing transportation emissions, ${ }^{7,57}$ though we find that for RCP 4.5, the regional analysis of which was shown previously in Figure 5, the impacts of transportation BC in regions such as the U.S. is negated by coreduction of reflective aerosols. However, we find a net negative forcing from the transportation sector following the three other RCPs in the U.S., Canada, Europe, Russia, and Japan, thus underscoring the importance of considering multiple future scenarios. The largest variability between RCPs occurs for the biomass burning DRFs; the domestic and industry emissions from China also have large DRFs which are highly variable across RCPs. Energy and agricultural DRFs are consistently positive and negative, respectively, across nearly all regions and RCPs.

The total global DRFs from each sector and their contributions by species are shown in Figure 5. DRFs from the industrial sector are largest in magnitude for the lowest greenhouse gas scenario (RCP 2.6) for $\mathrm{BC}, \mathrm{OC}$, and $\mathrm{SO}_{2}$. In contrast, $\mathrm{BC}$ DRFs for the transportation and domestic sectors are smaller in RCP 2.6 than RCP 8.5. RCP 6.0 has smaller
DRFs for $\mathrm{BC}, \mathrm{OC}$, and $\mathrm{SO}_{2}$ relative to the other scenarios. The total global DRF from $\mathrm{SO}_{2}, \mathrm{BC}$ and $\mathrm{OC}$ throughout many of the sectors combines to yield a net DRF close to zero, with the exception of energy and forest fire emissions. A significant driver of the overall DRF across all sectors is $\mathrm{NH}_{3}$ from agricultural emissions, modulation of which contributes to RCP 8.5 having a negative DRF and RCP 4.5 a positive DRF. These are again likely uppers estimate of $\mathrm{NH}_{3} \mathrm{DRF}$.

\section{DISCUSSION}

The results presented here are limited in several regards. The DRF efficiencies come from a single modeling framework, and thus do not reflect uncertainty in the underlying model and emissions, ${ }^{58-61}$ the former aspect alone can have a large impact on aerosol DRF even under unified emissions. ${ }^{62}$ Application of yearly average RCP emissions does not account for key seasonalities, such as the biomass burning season in boreal areas being out-of-phase with seasons of peak albedo. Ignoring the potential for organic aerosol to form semiabsorptive (i.e., brown) particles, in addition to secondary formation of organic aerosol, is a further simplification. The GEOS-Chem model's simple bulk-partitioning aerosol scheme assumes an external aerosol mixing state, which will not account for interspecies impacts on aerosol lifetime. ${ }^{63}$ Additionally, these results consider only direct aerosol effects, not accounting for indirect effects or impacts on greenhouse gases.

Without disregard for these caveats, we can still emphasize insights gleaned from evaluating radiative impacts at an unprecedented level of spatial, species and sectoral detail. That the DRF efficiencies ( $\mathrm{W} \mathrm{m} \mathrm{m}^{-2} /$ emission) calculated for $\mathrm{SO}_{2}, \mathrm{BC}, \mathrm{OC}$ and $\mathrm{NH}_{3}$ in each model grid cell demonstrate 
considerable variability at a spatial resolution much finer than previously considered in regionally based analysis is itself noteworthy, particularly given the commensurate variability in estimates of future emissions changes. Variations in the DRF efficiency can be considered a measure of the inequity of any mitigations strategy enacted on a per-emissions basis; such inequities have been shown here to be quite large for several sectors and species. Accounting for these variations, we assess the 2050 aerosol DRFs relative to present for multiple RCPs. The resulting range of DRFs indicates only a weak synergy between aerosol DRF and long-term radiative forcing targets attained primarily based on greenhouse gas targets. The balance of impacts from absorbing vs scattering aerosols is highly dependent upon sector, region and, in cases such as transportation emissions, which future scenario is considered. Further, inclusion of continually increasing $\mathrm{NH}_{3}$ emissions can significantly offset reductions of $\mathrm{SO}_{2}$ emissions (via replacement of ammonium sulfate with ammonium nitrate).

Efforts to mitigate impacts from individual species ${ }^{64,65}$ must thus be optimally targeted with regard to coemitted species. Resolving radiative forcing at resolutions closer to that at which emissions controls are actually enacted makes analysis of realistic policy options more viable, thereby affording inclusion of SLCF effects into the design of future scenarios.

\section{ASSOCIATED CONTENT}

\section{(S Supporting Information}

Details of the adjoint sensitivity validation and additional estimates of radiative forcings for preindustrial to present and future scenarios. This material is available free of charge via the Internet at http://pubs.acs.org.

\section{AUTHOR INFORMATION}

\section{Corresponding Author}

*Phone: 303-492-8716, e-mail: daven.henze@colorado.edu.

\section{Notes}

The authors declare no competing financial interest.

\section{ACKNOWLEDGMENTS}

D.K.H. recognizes support from the NASA New Investigator Program (NNH09ZDA001N), NASA AQAST (NNH09ZDA001N), and use of NASA HEC computing facilities. While this manuscript has been reviewed by EPA and approved for publication, it does not necessarily reflect official agency views or policies.

\section{REFERENCES}

(1) Forster, P. et al. Changes in Atmospheric Constituents and in Radiative Forcing. In Climate Change 2007: The Physical Science Basis. Contributions of working group I to the fourth Assessment Report on the Intergovernmental Panel on Climate Change, Technical Report; Solomon, S., Wuin, D., Manning, M., Chen, A., Marquis, M., Averyt, K., Tignor, M., Miller, H., Eds.; Cambridge University Press: Cambridge, 2007; p AR4.

(2) Dentener, F.; et al. The global atmospheric environment for the next generation. Environ. Sci. Technol. 2006, 40, 3586-3594.

(3) Ramanathan, V.; Xu, Y. Y. The Copenhagen accord for limiting global warming: Criteria, constraints, and available avenues. Proc. Natl. Acad. Sci. 2010, 107, 8055-8062.

(4) UNEP \& WMO. Integrated assessment of black carbon and tropospheric ozone: Summary for decision makers (2011).

(5) Koch, D.; Bond, T. C.; Streets, D.; Unger, N.; van der Werf, G. R. Global impacts of aerosols from particular source regions and sectors. J. Geophys. Res., [Atmos.] 2007, 112.
(6) Koch, D.; Bond, T. C.; Streets, D.; Unger, N. Linking future aerosol radiative forcing to shifts in source activities. Geophys. Res. Lett. 2007, 34.

(7) Fuglestvedt, J.; Berntsen, T.; Myhre, G.; Rypdal, K.; Skeie, R. B. Climate forcing from the transport sectors. Proc. Natl. Acad. Sci. 2008, 105, 454-458.

(8) Unger, N.; Shindell, D. T.; Koch, D. M., Streets, D. G. Air pollution radiative forcing from specific emissions sectors at 2030. J. Geophys. Res., [tmos.] 2008, 113.

(9) Shindell, D.; et al. Climate forcing and air quality change due to regional emissions reductions by economic sector. Atmos. Chem. Phys. 2008, 8, 7101-7113.

(10) Kloster, S. Influence of future air pollution mitigation strategies on total aerosol radiative forcing. Atmos. Chem. Phys. 2008, 8, 64056437.

(11) Hoyle, C. R; Myhre, G.; Isaksen, I. S. A. Present-day contribution of anthropogenic emissions from china to the global burden and radiative forcing of aerosol and ozone. Tellus, Ser. B 2009, $61,618-624$.

(12) Unger, N.; et al. Attribution of climate forcing to economic sectors. Proc. Natl. Acad. Sci. U. S. A. 2010, 107, 3382-3387.

(13) Hohne, N.; et al. Contributions of individual countries' emissions to climate change and their uncertainty. Clim. Change 2011, 106, 359-391.

(14) Bauer, S.; Menon, S. Aerosol direct, indirect, semidirect, and surface albedo effects from sector contributions based on the IPCC AR5 emissions for preindustrial and present-day conditions. J. Geophys. Res., [Atmos.] 117 (2012).

(15) Twomey, S. Influence of pollution on shortwave albedo of clouds. J. Atmos. Sci. 1977, 34, 1149-1152.

(16) Lohmann, U.; Feichter, J. Global indirect aerosol effects: A review. Atmos. Chem. Phys. 2005, 3, 715-737.

(17) Hansen, J.; Sato, M.; Ruedy, R. Radiative forcing and climate response. J. Geophys. Res., [Atmos.] 1997, 102, 6831-6864.

(18) Koch, D.; Del Genio, A. Black carbon semi-direct effects on cloud dover: Review and synthesis. Atmos. Chem. Phys. 2010, 10, 7685-7696.

(19) Unger, N.; Shindell, D.; Koch, D.; Streets, D. Cross influences of ozone and sulfate precursor emissions changes on air quality and climate. Proc. Natl. Acad. Sci. 2006, 103, 4377-4380.

(20) Shindell, D. T.; et al. Improved attribution of climate forcing to emissions. Science 2009, 326, 716-718.

(21) Lions, J. L. Optimal Control of Systems Governed by Partial Differential Equations; Springer-Verlag: Berlin, 1971.

(22) Sandu, A.; Daescu, D. N.; Carmichael, G. R.; Chai, T. F. Adjoint sensitivity analysis of regional air quality models. J. Comput. Phys. 2005, 204, 222-252.

(23) Bey, I.; et al. Global modeling of tropospheric chemistry with assimilated meteorology: Model description and evaluation. J. Geophys. Res., [Atmos.] 2001, 106, 23073-23095.

(24) Park, R. J.; Jacob, D. J.; Chin, M.; Martin, R. V. Sources of carbonaceous aerosols over the United States and implications for natural visibility. J. Geophys. Res., [Atmos.] 2003, 108.

(25) Park, R. J.; Jacob, D.; Field, B. D.; Yantosca, R.; Chin, M. Natural and transboundary pollution influences on sulfate-nitrateammonium aerosols in the United States: Implications for policy. J. Geophys. Res., [Atmos.] 109 (2004).

(26) Binkowski, F. S.; Roselle, S. J. Models-3 community multiscale air quality (CMAQ) model aerosol component-1. Model description. J. Geophys. Res., [Atmos.] 108 (2003).

(27) Jacob, D. J.; Liu, H.; Mari, C.; Yantosca, B. M. Harvard wet deposition scheme for GMI, 2000. http://gmi.gsfc.nasa.gov/models/ jacob_wetdep.pdf (accessed).

(28) Evans, M. J.; Jacob, D. J. Impact of new laboratory studies of $\mathrm{N}_{2} \mathrm{O}_{5}$ hydrolysis on global model budgets of tropospheric nitrogen oxides, ozone, and OH. Geophys. Res. Lett. 32 (2005).

(29) Martin, R. V.; Jacob, D. J.; Yantosca, R. M.; Chin, M.; Ginoux, P. Global and regional decreases in tropospheric oxidants from 
photochemical effects of aerosols. J. Geophys. Res., [Atmos.] 108 (2003).

(30) Olivier, J. G. J. et al. Applications of EDGAR Includinga Description of EDGAR 3.2: Reference Database with Trend Data for 1970-1995, RIVM report $773301001 / \mathrm{NRP}$ report 410200051 ; RIVM: Bilthoven, 2001.

(31) Bond, T. C. et al. Historical emissions of black and organic carbon aerosol from energy-related combustion, 1850-2000. Global Biogeochem. Cycles 21 (2007).

(32) van Donkelaar, A. Analysis of aircraft and satellite measurements from the intercontinental chemical transport experiment (INTEX-B) to quantify long-range transport of East Asian Sulfur to Canada. Atmos. Chem. Phys. 2008, 8, 2999-3014.

(33) van der Werf, G. R.; et al. Estimates of fire emissions from an active deforestation region in the southern amazon based on satellite data and biogeochemical modelling. Biogeosciences 2009, 6, 235-249.

(34) Yevich, R.; Logan, J. A. An assessment of biofuel use and burning of agricultural waste in the developing world. Global Biogeochem. Cycles 17 (2003).

(35) Wesely, M. L. Parameterization of surface resistances to gaseous dry deposition in regional-scale numerical-models. Atmos. Environ. 1989, 23, 1293-1304.

(36) Liu, H. Y.; Jacob, D. J.; Bey, I.; Yantosca, R. M. Constraints from $\mathrm{Pb}-210$ and $\mathrm{Be}-7$ on wet deposition and transport in a global threedimensional chemical tracer model driven by assimilated meteorological fields. J. Geophys. Res., [Atmos.] 2001, 106, 12109-12128.

(37) Martin, S. T.; et al. Effects of the physical state of tropospheric ammonium-sulfate-nitrate particles on global aerosol direct radiative forcing. Atmos. Chem. Phys. 2004, 4, 183-214.

(38) Koepke, P.; Hess, M.; Schult, I.; Shettle, E. P. Global aerosol data set. Tech. Rep. (1997).

(39) Chin, M.; et al. Tropospheric aerosol optical thickness from the GOCART model and comparisons with satellite and Sun photometer measurements. J. Atmos. Sci. 2002, 59, 461-483.

(40) Chung, S. H.; Seinfeld, J. H. Global distribution and climate forcing of carbonaceous aerosols. J. Geophys. Res., [Atmos.] 2002, 107, 4407.

(41) Bond, T. C.; Bergstrom, R. W. Light absorption by carbonaceous particles: An investigative review. Aerosol Sci. Technol. 2006, 40, 27-67.

(42) Spurr, R. J. D.; Kurosu, T. P.; Chance, K. V. A linearized discrete ordinate radiative transfer model for atmospheric remote-sensing retrieval. J. Quant. Spectrosc. Radiat. Transfer 2001, 68, 689-735.

(43) Spurr, R. J. D. Simultaneous derivation of intensities and weighting functions in a general pseudo-spherical discrete ordinate radiative transfer treatment. J. Quant. Spectrosc. Radiat. Transfer 2002, $75,129-175$.

(44) Koelemeijer, R. B. A.; de Haan, J. F.; Stammes, P. A database of spectral surface reflectivity in the range $335-772 \mathrm{~nm}$ derived from 5.5 years of GOME observations. J. Geophys. Res., [Atmos.] 108 (2003).

(45) Kinne, S.; et al. An AeroCom initial assessment - optical properties in aerosol component modules of global models. Atmos. Chem. Phys. 2006, 6, 1815-1834.

(46) Lamarque, J. F. Historical (18502000) gridded anthropogenic and biomass burning emissions of reactive gases and aerosols: Methodology and application. Atmos. Chem. Phys. 2010, 10, 70177039.

(47) Henze, D. K.; Hakami, A.; Seinfeld, J. H. Development of the adjoint of GEOS-Chem. Atmos. Chem. Phys. 2007, 7, 2413-2433.

(48) West, J. J.; Pilinis, C.; Nenes, A.; Pandis, S. N. Marginal direct climate forcing by atmospheric aerosols. Atmos. Environ. 1998, 32, 2531-2542.

(49) Moss, R. H.; et al. The next generation of scenarios for climate change research and assessment. Nature 2010, 463, 747-756.

(50) Riahi, K.; Gruebler, A.; Nakicenovic, N. Scenarios of long-term socio-economic and environmental development under climate stabilization. Technol. Forecast. Social Change 2007, 74, 887-935.

(51) Fujino, J.; Nair, R.; Kainuma, M.; Masui, T.; Matsuoka, Y. Multigas mitigation analysis on stabiliization scenarios using AIM global model. Multigas Mitigation and Climate Policy. The Energy Journal Special Issue (2006).

(52) Hojioka, Y.; Matsuoka, Y.; Nishimoto, H.; Masui, M.; Kainuma, M. Global GHG emissions scenarios under GHG concentration stabilization targets. J. Global Environ. Eng. 2008, 13, 97-108.

(53) Smith, S. J.; Wigley, T. M. L. Multi-gas forcing stabilization with the MiniCAM. Energy J. 2006, 373-391.

(54) Clarke, L.; et al. Scenarios of greenhouse gas emissions and atmospheric concentrations. sub-report 2.1a of synthesis and assessment product 2.1. Tech. Rep. 2007, RCP45.

(55) Wise, M. A.; et al. Implications of limiting $\mathrm{CO}_{2}$ concentrations for land use and energy. Science 2009, 324, 1183-1186.

(56) van Vuuren, D. P.; et al. Stabilizing greenhouse gas concentrations at low levels: An assessment of reduction strategies and costs. Clim. Change 2007, 81, 119-159.

(57) Shindell, D.; et al. Climate, health, agricultural and economic impacts of tighter vehicle-emission standards. Nat. Clim. Change 2011, 1, 59-66.

(58) Lee, C. et al. Retrieval of vertical columns of sulfur dioxide from SCIAMACHY and OMI: Air mass factor algorithm development, validation, and error analysis. J. Geophys. Res., [Atmos.] 116 (2009).

(59) Shephard, M. W.; et al. TES ammonia retrieval strategy and global observations of the spatial and seasonal variabiity of ammonia. Atmos. Chem. Phys. 2011, 11, 1074310763.

(60) Koch, D.; et al. Evaluation of black carbon estimations in global aerosol models. Atmos. Chem. Phys. 2009, 9, 9001-9026.

(61) Fu, T. M. Carbonaceous aerosols in China: Top-down constraints on primary sources and estimation of secondary contribution. Atmos. Chem. Phys. 2011, 2725-2746.

(62) Schulz, M.; et al. Radiative forcing by aerosols as derived from the AeroCom present-day and pre-industrial simulations. Atmos. Chem. Phys. 2006, 6, 5225-5246.

(63) Stier, P., Seinfeld, J. H.; Kinne, S.; Feichter, J.; Boucher, O. Impact of nonabsorbing anthropogenic aerosols on clear-sky atmospheric absorption. J. Geophys. Res., [Atmos.] 2006, 111.

(64) Penner, J. E.; et al. Short-lived uncertainty? Nat. Geosci. 2010, 3, 587-588.

(65) Kopp, R. E.; Mauzerall, D. L. Assessing the climatic benefits of black carbon mitigation. Proc. Natl. Acad. Sci. 2010, 107, 1170311708 . 